\title{
Measuring snow in 3-D using X-ray tomography: assessment of visualization techniques
}

\author{
M. HEGGLI, B. KÖCHLE, M. MATZL, B.R. PINZER, F. RICHE, S. STEINER, \\ D. STEINFELD, M. SCHNEEBELI
}

\author{
WSL Institute for Snow and Avalanche Research SLF, Flüelastrasse 11, CH-7260 Davos-Dorf, Switzerland \\ E-mail: schneebeli@slf.ch
}

\begin{abstract}
Snow hides its true structure from easy visual observation. One reason is that ice is transparent, so the three-dimensional (3-D) structure is impossible to disentangle. 3-D reconstruction is essential to understand the physical and mechanical properties of snow. In recent years, the techniques to measure and visualize snow in 3-D have improved tremendously. X-ray microtomography is much more user-friendly than the older microtome sectioning techniques. We show different techniques to measure cast and natural snow samples and the steps necessary to produce high-quality data. The simplest way is 3-D renderings. Imaging snow in 3-D definitively challenges our previous view of a snowpack consisting of particles as traditionally seen on a crystal card.
\end{abstract}

\section{INTRODUCTION}

Traditionally, the shape of snow crystals is studied on a snow crystal card or under a binocular using transmitted light (LaChapelle, 1992). However, through the process of sampling and preparing the snow on the card the information about the original three-dimensional (3-D) architecture and connectivity of the snow crystals in the snowpack is lost and snow is implicitly considered as a material composed of individual grains or crystals. However, most mechanical and physical properties can only be understood and predicted by considering the 3-D microstructure of the snow. Physical properties that are intrinsically dependent on the 3-D structure are, for example, thermal conductivity (Schneebeli and Sokratov, 2004; Pinzer and Schneebeli, 2009b), electromagnetic reflectance (Toure and others, 2008), mechanical strength (Schneebeli and others, 1999; Schneebeli, 2004) and permeability (Albert, 2002; Courville and others, 2010). Furthermore, the 3-D data can serve as starting structures for numerical simulations (Schneebeli, 2004; Kaempfer and others, 2005; Kaempfer and Plapp, 2009; Pinzer and others, 2010). The methods used to measure the 3-D structure of snow are serial sectioning (Perla and others, 1986; Good, 1987), microcomputed tomography (micro-CT) of snow samples filled with contrast agent (Coléou and others, 2001) and direct micro-CT imaging of the snow (Freitag and others, 2004; Schneebeli, 2004). Serial sectioning is a destructive process in which subsequent sections of a cast snow sample are produced with a microtome and photographed. Micro-CT, on the other hand, is non-destructive and much faster. Here we give an overview of how to prepare samples for imaging, an overview of the image treatment and the best use of the different visualization techniques.

\section{MEASURING 3-D SNOW STRUCTURE}

\section{Serial sectioning}

Serial sectioning requires a good optical contrast between ice and the filler. A high contrast is achieved in cases where the diethyl phthalate (DEP) is not crystallized. Experience showed that the crystallization process of DEP is unpredictable, so good images are often difficult to obtain. In addition, the size is limited to a sample size of a few millimeters. Compared to the serial sectioning method, micro-CT allows much faster acquisition of images of large samples.

\section{Microcomputed tomography}

Micro-CT is a non-destructive method to measure the 3-D structure of samples (Banhart, 2008). It makes it possible to scan the same snow sample multiple times and follow changes of the microstructure. Currently, the technique is used to investigate isothermal metamorphism (Kaempfer and Schneebeli, 2007), temperature gradient metamorphism (Pinzer and Schneebeli, 2009b) and mechanical deformation (Theile and others, 2009). In micro-CT a large number of projections (usually 1000) are acquired using an X-ray beam transmitted through the sample. Image contrast is based on the different X-ray absorption of the different phases (ice and air) in the sample. The original geometry is reconstructed from the projections (sinograms) by, for example, a filtered back-projection algorithm. A stack of these cross sections is a 3-D dataset that contains the full information on the 3-D structure of the sample. Kerbrat and others (2008) show that the effective resolution of the microCT is sufficient to resolve the features of the ice surface in most snow types, even for fresh snow.

Microtomography is possible both with synchrotronbased and laboratory X-ray sources. Synchrotron-based instruments have sub-micrometer resolution and short acquisition times because of the coherence and high brilliance of synchrotron radiation. However, snow measurements at synchrotron sources are rather cumbersome because special cooled sample holders are required since the laboratory cannot usually be cooled to subzero temperature. In addition, the access to beam time at synchrotrons is in most cases very restrictive.

For our measurements we use both a $\mu \mathrm{CT} 40$ and a $\mu \mathrm{CT} 80$ (Scanco Medical, Switzerland) scanner with an X-ray tube. The instruments are operated in a cold room at -15 to $-20^{\circ} \mathrm{C}$. Therefore, further cooling of the sample is not necessary.

\section{Time-lapse tomography}

Micro-CT is a non-destructive measurement method. In a specific sample holder, the same sample can be measured 

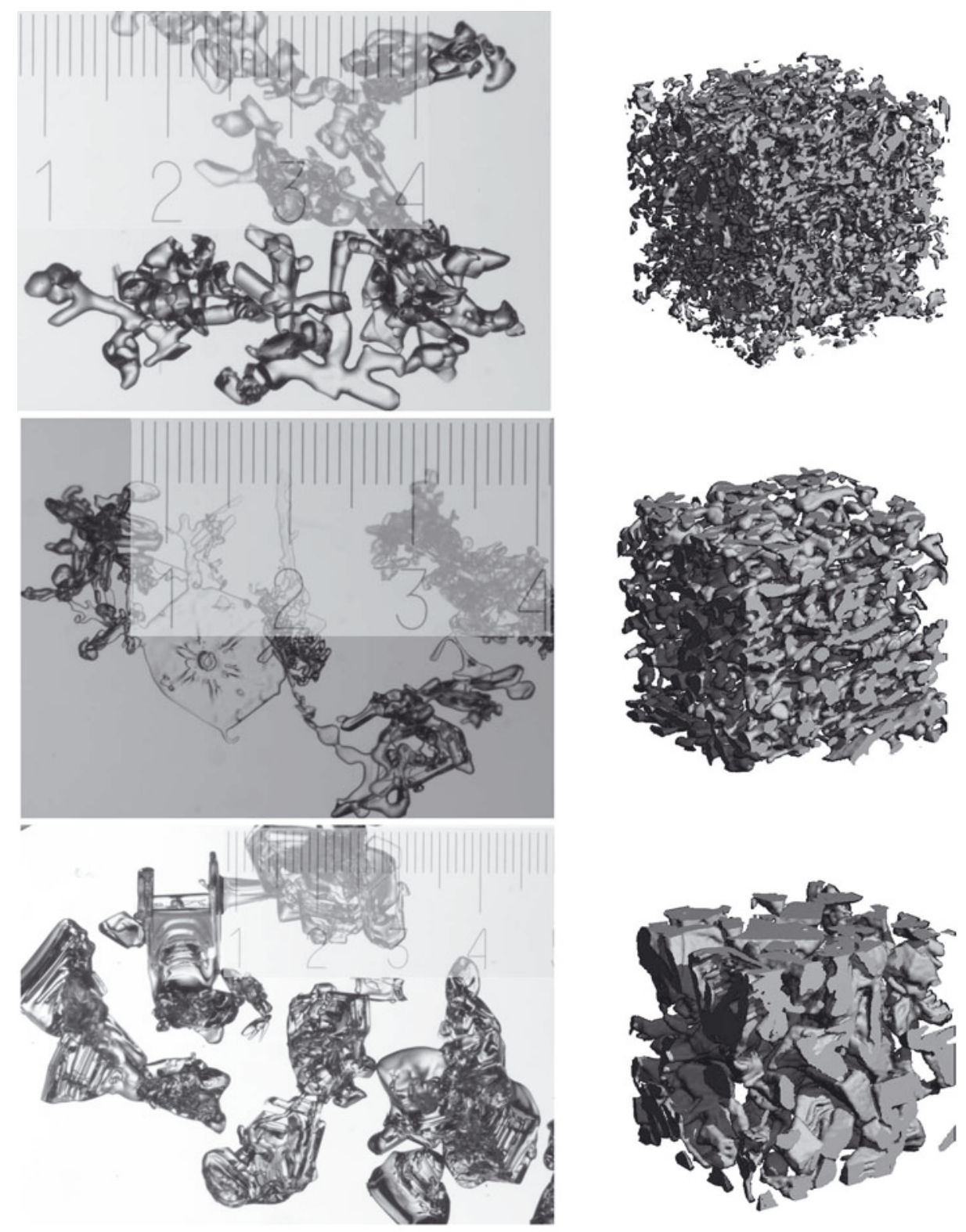

Fig. 1. Typical snow types presented as snow grains (left) and as surface renderings (right) (volume size $3.6 \times 3.6 \times 3.6 \mathrm{~mm}^{3}$; voxel size $\left.18 \times 18 \times 18 \mu \mathrm{m}^{3}\right)$. The traditional grain images do not contain any information about the 3 -D structure and the pores (scales in mm) (color anaglyphs at http://tinyurl.com/snow-visualization).

many times. This so-called time-lapse tomography makes it possible to study the temporal evolution of a snow sample. Processes that can be studied include settling of a snow sample under a static weight (Theile, 2010) and, using a special instrumented sample holder (Pinzer and Schneebeli, 2009a), the snow metamorphism under both constant (Schneebeli and Sokratov, 2004) and alternating temperature gradients (Pinzer and Schneebeli, 2009b). Images from a series of time-steps can be collected into an animated movie. This illustrates the changes of the structure and helps to understand the processes involved.

\section{SNOW SAMPLING AND CASTING}

Usually, snow is sampled in the field, sometimes in remote locations. Therefore, a laboratory with suitable instrumentation for microstructural analysis is often not nearby. The fragile snow structure is susceptible to rapid changes due to snow metamorphism. Hence it is often necessary to conserve the samples to prevent structural changes in the samples before they can be analyzed in the laboratory. For this purpose, the snow samples are cast with a solidifying liquid. Several substances can be used such as 1-chloronaphthalene (Flin and others, 2003), dimethyl phthalate (Perla and others, 1986) and DEP (Heggli and others, 2009). We prefer to use DEP because it is the least toxic, environmentally relatively well degradable and comparatively cheap substance.

Briefly, the casting process is performed as follows: A snow sample is put in a sample collection box. The box is slowly filled with dyed DEP that has been preconditioned to a temperature of -2 to $-5^{\circ} \mathrm{C}$. When the snow sample is completely filled with the DEP, the sample box is put in an insulated container and packed with dry ice on all sides. After $\sim 1$ hour, DEP has solidified and the samples can be stored at $-20^{\circ} \mathrm{C}$ for several months. 


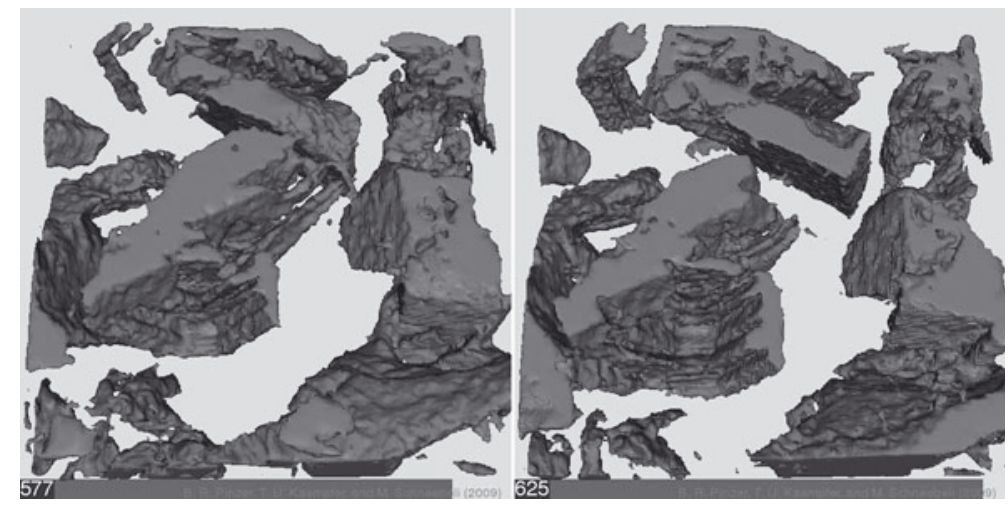

Fig. 2. Two images separated by 2 days from a time-lapse movie. The snow was under a constant temperature gradient of $\sim 50 \mathrm{Km}^{-1}$. The image at time 577 hours compared to time 625 hours shows where water vapor was deposited as ice, and where ice sublimated. The reference frame was constant; the crystals grow downwards, towards the vapor source.

Until recently, DEP cast snow samples could only be analyzed by serial sectioning because of the lack of X-ray contrast between ice and DEP (Schneebeli, 2001). This was often difficult because recrystallization of the DEP made automatic image analysis difficult if not impossible. However, recently we have presented a novel method that allows analysis of cast samples with micro-CT (Heggli and others, 2009). For this replica method, the cast snow samples are stored in a vacuum container for several days until all ice has sublimated. The resulting negative (replica) of the original structure can be analyzed with micro-CT. Inversion of the replica image by image processing in the computer yields an image of the original snow structure. In the field, it is difficult to cast samples completely free of air inclusions. When using the replica method, remaining air bubbles are interpreted as part of the ice structure. Therefore, we improved the method by acquiring a CT scan of the cast sample before ice sublimation. This scan and the scan after ice sublimation are matched using an image registration method. All volumes that are air in both scans actually belong to the pore space. Hence, they must be subtracted from the ice structure of the CT scan after ice sublimation.

\section{VISUALIZATION METHODS}

Both serial sectioning and micro-CT yield stacks of twodimensional slices in the first step. Such a stack of slices contains the full 3-D information of a sample. The slices can be viewed as such, but it is often more instructive to generate 3-D visualizations. There are several possibilities of doing so, as explained in the following.

\section{Image processing}

The micro-CT instrument provides a stack of grayscale images that form a 3-D dataset. Processing of these images is necessary to extract the 3-D structure information. Usually, it is necessary to filter the images first in order to reduce image noise. Median and Gaussian filters are suitable options.

In a second step the images must be segmented. This means that for each voxel it has to be decided to which phase it belongs based on its gray value. The most straightforward segmentation method uses a fixed threshold. The result is a binary 3-D image in which each voxel belongs to either of two phases, i.e. in the case of snow ice or air. The binary 3-D image can subsequently be used to generate different visualizations such as surface renderings, anaglyphs, animations and physical models.

\section{Surface renderings}

3-D surface renderings give an illusion of a 3-D structure by using central perspective and only displaying parts of the structure that are visible to the observer (i.e. hiding parts that are covered by other parts closer to the observer). In a surface rendering, a structure appears as it would appear in a conventional photograph (Fig. 1 right). However, most people have difficulty interpreting the real 3-D structure from such pictures.

\section{Anaglyphs}

Anaglyph images have the advantage of giving a truly 3-D visual impression. The generation of such images is straightforward: two surface renderings, one for the left, one for the right eye, are needed. The viewing angle of each should differ by $\sim 6^{\circ}$. Special software (e.g. Imagel (Rasband, 2011) with plug-in 'Two Shot Anaglyph') can merge the two pictures into one superimposed picture. The left image is colored red and the right one cyan. Then the two images are merged. For viewing, red-cyan goggles are required. Anaglyphs can easily be used in presentations given that the audience can be equipped with red-cyan goggles. A disadvantage for printed products is that color print is required. In our experience, anaglyphs are the cheapest and most efficient way to give observers the true 3-D impression. In addition, structural features can be explained on a projection screen 'in 3-D'. Examples of snow visualizations using anaglyphs are available online at http://tinyurl.com/ snow-visualization.

\section{Animations}

Animations that show a structure from different viewing angles are an appealing option for presentations. Such animations are composed of a series of surface renderings that are displayed one after the other. The parallax in such animations enhances the 3-D impression.

Furthermore, animations can be used to visualize the results of time-lapse tomography studies. The temporal evolution of a snow sample can be seen in an animated movie and helps with understanding the underlying processes of mass transport and heat flux. The dynamic aspect is illustrated in Figure 2 where freeze-frames were taken from a movie of temperature gradient metamorphism. 


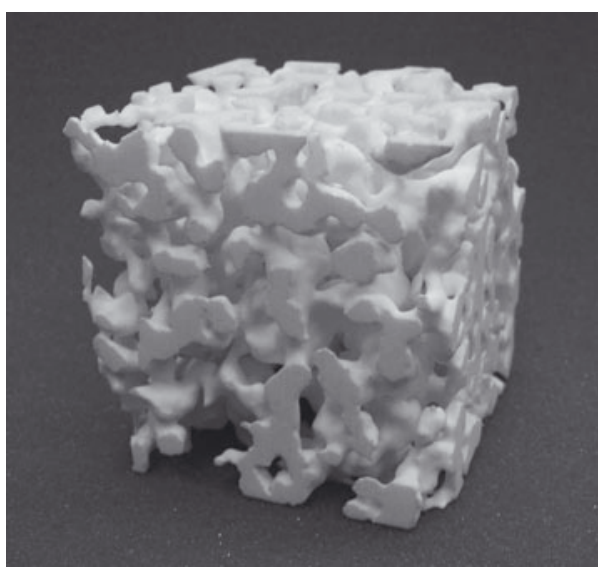

Fig. 3. Physical 3-D model of snow microstructure (large rounded grains, RGlg) can be used for exhibitions and teaching (size $10 \times 10 \times 10 \mathrm{~cm}^{3}, 25 \times$ magnification). The model was produced based on micro-CT data by laser sintering.

\section{Physical 3-D models}

A tangible 3-D model is optimal for a classroom or an exhibition (Fig. 3). The viewer can experience the different snow structures 'hands-on' and viewing the structures from different sides. This facilitates understanding of the 3-D architecture of the snow structure. 3-D models can be produced based on 3-D tomography datasets by rapid prototyping methods such as laser sintering from diverse plastics. However, production cost is still substantial, and the models are not easy to distribute.

\section{EXAMPLES}

\section{Typical snow types and their 3-D representation}

In Figure 1 we show three typical snow types. They are shown as grains (left) and as surface renderings (right). Anaglyph images of the same snow types are available online (http://tinyurl.com/snow-visualization). The surface renderings only give the illusion of $3-D$, whereas the anaglyphs generate a much more realistic 3-D effect. The respective snow types are decomposing snow (DFdc, according to Fierz and others 2009), small rounded grains (RGsr) and depth hoar (DHcp). Traditional grain images (Fig. 1 left) were made using a binocular microscope equipped with a digital camera. These images contain only information about the individual crystals, but lack any information about the 3-D connectivity of the crystal with its surroundings. The micro-CT data, on the other hand, contain in principle the full 3-D information about the snow structure. However, some experience is required to interpret the 3 -D structure in surface renderings (Fig. 1 bottom left) because the impression of depth is limited. Anaglyphs, on the other hand, enhance the perception of depth. This facilitates understanding of the true structure, especially of the pore space (anaglyph images online; decomposed snow: http://tinyurl.com/67bptdv; rounded snow: http://tinyurl. com/6e6rq92; depth hoar: http://tinyurl.com/6boruss).

\section{Layered snow samples}

Figure 4 shows a layered snow sample retrieved near the surface of the snowpack in Davos, Switzerland. The snow sample was cast with DEP in the field and then processed

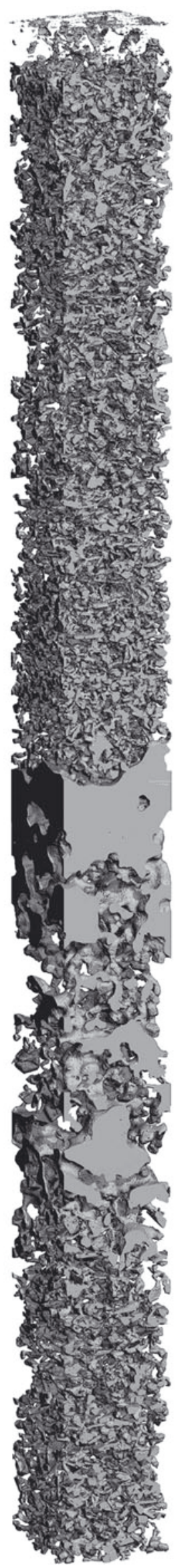

Fig. 4. Fragile layered snow samples can be visualized using the replica method. The bonding between different layers in a snowpack is visible. This sample shows the top $66 \mathrm{~mm}$ of a snowpack from Davos including a melt crust (sample size $5 \times$ $5 \times 66 \mathrm{~mm}^{3}$; voxel size $10 \times 10 \times 10 \mu \mathrm{m}^{3}$ ). 


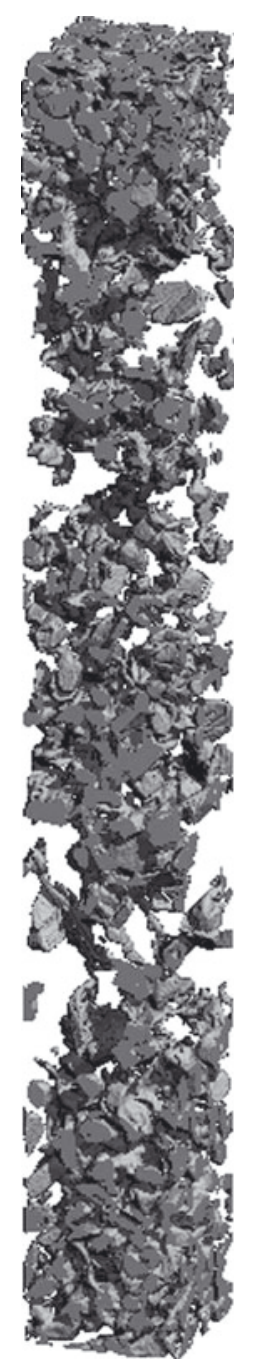

Fig. 5. Layer of subsurface hoar in the snowpack (Totalp, Davos, Switzerland, 14 January 2010 , volume $3 \times 3 \times 25 \mathrm{~mm}$; voxel size $10 \times 10 \times 10 \mu \mathrm{m})$. The anaglyph image is online at http://tinyurl. com/6ye9z73.

according to the replica method (Heggli and others, 2009). The 3-D structure of the sample was measured with a $\mu \mathrm{CT} 40$. A total of 6600 slices were measured corresponding to a sample height of $66 \mathrm{~mm}$. The size of each voxel (volume element) is $10 \times 10 \times 10 \mu \mathrm{m}^{3}$. In the volume rendering we can recognize several different layers including a melt crust.

The profile in Figure 5 was collected at Totalp near Davos on 14 January 2010. It shows a layer of subsurface hoar a few centimeters below the snow surface enclosed between two layers of higher-density snow. The anaglyph image (http://tinyurl.com/6ye9z73) facilitates interpretation of the 3-D structure, especially of the subsurface hoar weak layer.

The method presented here helps us to understand the shape and structure of layers that are hard to see in a hand profile. Furthermore, it makes it possible to study the interconnection between adjacent layers in the snowpack.

\section{CONCLUSION}

Micro-CT reproduces the original 3-D connectivity of the crystals and layers in a snowpack. Furthermore, it allows study of the structure of the pore space, which is inaccessible when looking at traditional grain images, but very important for processes such as permeability and fracture. However, the appearance of snow in simple 3-D renderings cannot be fully grasped by most observers. Therefore, true 3-D visualizations using anaglyphs are necessary to facilitate understanding of the structure. Information about the 3-D structure of both the ice skeleton and the pore space is essential to realize that snow is a sintered material and to understand its metamorphism and physical properties. Such visualizations are an important tool in teaching snow physics and avalanche formation.

\section{ACKNOWLEDGEMENTS}

W. Good and G. Krüsi initiated 3-D visualization of snow in the 1980s. We are grateful for their pioneering work.

\section{REFERENCES}

Albert, M.R. 2002. Effects of snow and firn ventilation on sublimation rates. Ann. Glaciol., 35, 52-56.

Banhart, J. 2008. Advanced tomographic methods in materials research and engineering. Oxford, etc., Oxford University Press.

Coléou, C., B. Lesaffre, J.B. Brzoska, W. Ludwig and E. Boller. 2001. Three-dimensional snow images by X-ray microtomography. Ann. Glaciol., 32, 75-81.

Courville, Z., M. Hörhold, M. Hopkins and M. Albert. 2010. Lattice-Boltzmann modeling of the air permeability of polar firn. J. Geophys. Res., 115(F4), F04032. (10.1029/2009JF001549.)

Fierz, C. and 8 others. 2009. The international classification for seasonal snow on the ground. Paris, UNESCO-International Hydrologic Programme. (IHP Technical Documents in Hydrology 83.)

Flin, F., J.B. Brzoska, B. Lesaffre, C. Coléou and R.A. Pieritz. 2003. Full three-dimensional modelling of curvature-dependent snow metamorphism: first results and comparison with experimental tomographic data. J. Phys. D, 36(10A), A49-A54.

Freitag, J., F. Wilhelms and S. Kipfstuhl. 2004. Microstructuredependent densification of polar firn derived from X-ray microtomography. J. Glaciol., 50(169), 243-250.

Good, W. 1987. Thin sections, serial cuts and 3-D analysis of snow. IAHS Publ. 162 (Symposium at Davos 1986 - Avalanche Formation, Movement and Effects), 35-48.

Heggli, M., E. Frei and M. Schneebeli. 2009. Snow replica method for three-dimensional X-ray microtomographic imaging. J. Glaciol., 55(192), 631-639.

Kaempfer, T.U. and M. Plapp. 2009. Phase-field modeling of dry snow metamorphism. Phys. Rev. E, 79(3), 031502. (10.1103/ PhysRevE.79.031502.)

Kaempfer, T.U. and M. Schneebeli. 2007. Observation of isothermal metamorphism of new snow and interpretation as a sintering process. J. Geophys. Res., 112(D24), D24101. (10.1029/2007JD009047.)

Kaempfer, T.U., M. Schneebeli and S.A. Sokratov. 2005. A microstructural approach to model heat transfer in snow. Geophys. Res. Lett., 32(21), L21503. (10.1029/2005GL023873.)

Kerbrat, M., B. Pinzer, T. Huthwelker, H.W. Gäggeler, M. Ammann and M. Schneebeli. 2008. Measuring the specific surface area of snow with X-ray tomography and gas adsorption: comparison and implications for surface smoothness. Atmos. Chem. Phys., 8(5), 1261-1275.

LaChapelle, E.R. 1992. Field guide to snow crystals. Cambridge, International Glaciological Society.

Perla, R.I., J. Dozier and R.E. Davis. 1986. Preparation of serial sections in dry snow specimens. J. Microsc., 141, 111-114.

Pinzer, B. and M. Schneebeli. 2009a. Breeding snow: an instrumented sample holder for simultaneous tomographic and thermal studies. Measure. Sci. Technol., 20(9), 095705. (10.1088/0957-0233/20/9/095705.) 
Pinzer, B.R. and M. Schneebeli. 2009b. Snow metamorphism under alternating temperature gradients: morphology and recrystallization in surface snow. Geophys. Res. Lett., 36(23), L23503. (10.1029/2009GL039618.)

Pinzer, B.R., M. Kerbrat, T. Huthwelker, H.W. Gäggeler, M. Schneebeli and M. Ammann. 2010. Diffusion of NOx and HONO in snow: a laboratory study. J. Geophys. Res., 115(D3), D03304. (10.1029/2009JD012459.)

Rasband, W.S. 2011. ImageJ program. Bethesda, MA, National Institutes of Health.

Schneebeli, M. 2001. Three-dimensional snow: what snow really looks like. In Proceedings of the International Snow Science Workshop, 1-6 October 2000, Big Sky, Montana. Bozeman, MT, American Avalanche Association, 407-408.

Schneebeli, M. 2004. Numerical simulation of elastic stress in the microstructure of snow. Ann. Glaciol., 38, 339-342.
Schneebeli, M. and S.A. Sokratov. 2004. Tomography of temperature gradient metamorphism of snow and associated changes in heat conductivity. Hydrol. Process., 18(18), 3655-3665.

Schneebeli, M., C. Pielmeier and J.B. Johnson. 1999. Measuring snow microstructure and hardness using a high resolution penetrometer. Cold Reg. Sci. Technol., 30(1-3), 101-114.

Theile, T. 2010. Three-dimensional structural image analysis and mechanics of snow. (Dr.-Ing. thesis, Technical University of Dortmund.)

Theile, T., D. Szabo, A. Luthi, H. Rhyner and M. Schneebeli. 2009. Mechanics of the ski-snow contact. Tribol. Lett., 36(3), 223-231.

Toure, A.M., K. Goïta, A. Royer, C. Mätzler and M. Schneebeli. 2008. Near-infrared digital photography to estimate snow correlation length for microwave emission modeling. Appl. Opt., 47(36), 6723-6733. 